\title{
Objetivos transnacionales: El cine español del nuevo milenio
}

\author{
Cristina Martínez-Carazo \\ University of California, Davis \\ cmmartinezcarazo@ucdavis.edu
}

\begin{abstract}
Although transnationality as a phenomenon is as old as film, the contemporary reflection on this topic and the plurality of approaches that converge on it have opened new lines of analysis to evaluate the impact that this reality exerts on the film industry. My intention in this study is to propose a typology that reflects the impact of transnationality in the specific case of Spanish film to explore the dynamics that control our cinematic production in the third millennium. I propose six segments to structure my approach to the Spanish film industry: 1. Production modes; 2. Transnational subjects; 3. Aesthetic registers; 4. Themes; 5. Ethics and ideology; 6. Critical and moviegoer reception. Within this framework, I will explore the dialectics between the national essence of Spanish film and its transnationality, the impact of different financial models, the multidirectional movements of our actors and directors, esthetic
\end{abstract}


influences, the ethics of the industry and the response of critics and viewers to a film industry that swings between preserving and erasing its identity markers.

Keywords: Transnationality; identity; typology; production; ethics; esthetics; ideology; reception

\section{Resumen}

Si bien la transnacionalidad del cine es casi tan vieja como el cine mismo, la reflexión actual sobre esta cuestión y la pluralidad de vectores que convergen en ella, han abierto nuevas vías de análisis para aquilatar el impacto que esta realidad ejerce en la industria fílmica. Mi intención en este estudio es proponer una tipología que conecte el concepto de transnacionalidad con el caso concreto del cine español para ayudar a dilucidar la mecánica que rige el presente de nuestra producción cinematográfica. Estableceré para ello seis segmentos a partir de los cuales se estructurará mi acercamiento: 1. Modos de producción; 2. sujetos transnacionales; 3. registros estéticos; 4 . repertorio temático; 5. componente ético e ideológico y 6 . recepción crítica y espectatorial. Dentro de este marco conceptual exploraré la dialéctica entre la esencia nacional del cine español y su transnacionalidad, el impacto de los modelos de financiación en el proceso de creación, los movimientos multidireccionales de nuestros actores y directores, las influencias estéticas que atraviesan el cine español actual, las reflexiones a nivel ético derivadas de los condicionantes de la industria y las respuestas de la crítica y del público, tanto en España como en otros países, a un cine que se debate entre subrayar y diluir sus marcadores identitarios.

Palabras clave: Transnacionalidad; identidad; tipología; producción; ética; estética; ideología; recepción 
- i bien la "transnacionalidad" del cine es casi tan vieja como el cine - mismo, la reflexión actual sobre esta cuestión y la pluralidad de ángulos que convergen en ella, han abierto nuevas vías para aquilatar los múltiples significados que este término adquiere en nuestro presente global. Pocos debates sobre el séptimo arte han suscitado durante los últimos años tanta atención como el complejo entramado económico, ético, estético y político que apunta a disolver las fronteras de los cines nacionales y a expandir los parámetros de la producción cinematográfica actual. La diversidad de términos aplicados para describir esta nueva condición "apátrida" del cinetransnacional, híbrido, crossover cinema-da buena muestra de la pluralidad de matices que convergen en este proceso de reconceptualización.

El concepto de cine transnacional surge como respuesta a los cambios en los modelos de producción, distribución y exhibición inherentes a la industria cinematográfica actual y deriva de ahí su sentido y su forma. Se percibe así como un arte producido y consumido dentro de un marco geopolítico amplio, cuyos registros éticos, estéticos y económicos conectan y la vez trascienden diversos contextos nacionales, subrayando su liminalidad. En contraste con este modelo, el cine global exhibe una clara voluntad homogeneizadora, una borradura intencionada de identidades diversas que aspira a la indiferenciación cultural y a la imposición de una visión totalizadora que en gran medida agiliza la difusión y amplía la recepción.

Como bien indican Will Higbee and Song Hwee Lim “Whereas globalization is routinely applied to any and every process or relationship (political, social, cultural and economic) that crosses national boundaries, the transnational is more attuned to the scale, distribution and diversity of such exchanges and their impact at a local level as well as an understanding that they may have effects within and beyond the nation-state" (12).

Varios críticos ${ }^{1}$ se han acercado a la cuestión de la transnacionalidad para proponer definiciones y tipologías que simultáneamente delimitan y expanden 
el campo de reflexión. Sukhmani Khorana en su libro titulado Crossover Cinema: cross-cultural film from production to reception condensa la esencia híbrida de este modo de filmar y lo define como "an emerging form of cinema that crosses cultural borders at the stage of conceptualization and production and hence manifests a hybrid cinematic grammar at the textual level as well as crossing over in terms of its distribution and reception" (3). Si bien hay tantas definiciones como estudiosos del tema, la propuesta por Khorama demarca bien el terreno de la industria cinematográfica actual y ayuda a entender la disolución de fronteras inherente a este modo de filmar. Como bien refleja el título de un ensayo de lan Christie titulado "Where is National Cinema Today (and do we still need it?)" en lo que sí existe un consenso es en la necesidad de cuestionar el paradigma del cine nacional, percibido como una categoría insuficiente para explicar la diversidad de formaciones culturales que convergen en nuestro presente en la mayoría de los textos fílmicos.

Surge así la necesidad de llegar a una simbiosis entre un cine nacional de miras amplias que propicie en su proceso de formación condiciones óptimas para innovaciones industriales, formales e ideológicas y un cine transnacional que transcienda los limites de la nación sin desplazarla de este marco conceptual. Con este objetivo como referente se definen tres ejes en torno a los cuales se articula la reflexión: 1-la dialéctica entre lo local, nacional, transnacional y global; 2-la percepción de lo transnacional como un fenómeno regional; y 3 -la relevancia de los procesos asociados a la diáspora, exilio y postcolonialismo. El primer eje gira en torno a las limitaciones del modelo nacional y a la necesidad abarcar formaciones culturales y económicas que no caben dentro de los límites de la nación; el segundo aborda lo transnacional como un fenómeno regional en sentido amplio basándose en la existencia de una herencia cultural compartida y en un espacio geopolítico común; y el tercero se centra en cineastas y obras diaspóricas que subrayan los desequilibrios entre centro y márgenes, inclusión y exclusión, aceptación y 
rechazo, constatando en el proceso la inestabilidad de la nación y de la cultura nacional y el constante proceso de transformación al que se hayan sometidas.

Uno de los acercamientos más fructíferos al cine transnacional radica en la elaboración de tipologías basadas en una serie de criterios que ponen de manifiesto la necesidad de ampliar la reflexión y de trascender el ámbito de la financiación. La elaborada por Mette Hjort en "On the plurality of cinematic transnationalism" parte de dos rasgos asociados a este concepto: la resistencia a la globalización como homogeneización cultural y la necesidad de evitar que el aspecto económico eclipse los marcadores estéticos, sociales y políticos (15). A partir de aquí establece unas categorías (epiphanic transationalism, affinitive, milieu building, opportunistic, cosmopolitan, globalizing, auteurist, modernizing and experimental) basadas en criterios amplios y variados que dilatan el ámbito de análisis. Deborah Shaw en "Deconstructing and Reconstructing 'Transnational Cinema' " se mueve en un terreno más concreto y propone otra tipología basada en las siguientes variables: "transnational modes of production, distribution and exhibition, transnational modes of narration, cinema of globalization, multiple locations, exilic and diasporic film making, film and cultural exchange, transnational influences, transnational critical approaches, transnational viewing practices, transregional films, transnational stars, transnational directors, ethics of transnationalism, transnational collaborative networks, and national films" (52) que se entretejen para perfilar el alcance de la transnacionalidad cinematográfica.

Tomando dichos acercamientos como marco de referencia pretendo establecer una tipología aplicable al cine español con el fin de trazar un perfil más preciso de su transnacionalidad. Para ello esbozo seis segmentos en torno a los cuales se estructurará mi acercamiento: 1-Condicionantes industriales, 2-sujetos transnacionales, 3-registros estéticos, 4-repertorio temático y pluralidad espacial, 5-componente ético e ideológico, 6-recepción crítica y espectatorial. En dichas categorías que inevitablemente se superponen y se 
complementan a la vez que permiten segmentar el análisis, se refleja cómo España reconcilia una mirada hacia dentro y otra hacia fuera a la hora de articular su producción cinematográfica.

\section{Condicionantes industriales.}

Englobo en ellos producción, coproducción, distribución y exhibición de películas españolas, aspectos clave a la hora de entender la insuficiencia de la nación como marco de análisis. Como es bien sabido el problema más acuciante del cine español es la falta de financiación y uno de los modos de paliarlo es recurrir a las coproducciones ${ }^{2}$. Según los datos de la FAPAE (Federación de Asociaciones de Productores Audiovisuales Españoles) en 2013 se produjeron en España 174 largometrajes y 57 coproducciones. En el 2012 el festival de San Sebastián puso en marcha el Foro de Coproduccion Europa-America Latina con el fin de impulsar la colaboración entre profesionales de ambos espacios y abrir mercados internacionales.

Su precedente, el fondo de coproducción Ibermedia, creado en 1997 entre España, Portugal y América Latina (18 países, entre ellos Argentina, Bolivia, Chile, Colombia, Costa Rica, Cuba, Republica Dominicana, Ecuador, Guatemala, México, Panamá, Perú, Puerto Rico, Uruguay, Venezuela) persigue objetivos similares: promover el intercambio técnico y económico entre profesionales del medio audiovisual en los países miembros y desarrollar una industria del cine en Latino América que sea competitiva a nivel tecnológico y cultural en el mercado internacional. ${ }^{3}$

Más allá de las quejas asociadas a esta iniciativa-control desde España, endogamia, relación neocolonialista... - Ibermedia ha ayudado a diseminar el cine latinoamericano y español fuera de sus fronteras y a contrarrestar la irregular financiación por parte de los gobiernos correspondientes, como prueban los 108 proyectos que en el 2014 coprodujo con España, Argentina y Brasil a la cabeza. ${ }^{4}$ 
Indirectamente conectado con este fondo surge Cine en Construcción, iniciativa de Rencontres Cinémas D’Amérique Latine de Toulouse, adoptada en el 2001 por el Festival de San Sebastián y organizada como una competición para la provisión de fondos destinados a postproducción y distribución de cine independiente. A pesar de que se le reprocha el mismo espíritu neocolonialista que a Ibermedia y la misma voluntad de paliar "the imperial guilt" (Nuria Triana Toribio, 103) contribuye a perfilar un espacio transnacional valioso para atenuar la limitada visibilidad del cine latinoamericano en Europa. Europa y Lationoamérica operan así como "regiones naturales" para la difusión del cine en español, ${ }^{5}$ configurando lo que Libia Villazana denomina "transnational communities" (27).

Con Europa como marco, destacan dos programas clave para la financiación de películas: Media Plus 2007 y Eurimages. Media Plus 2007 es un programa de apoyo al sector audiovisual europeo, continuador de los programas Media Plus y Media Formación. Su periodo de actuación va del 2007 al 2013 y cuenta con una dotación económica de 755 millones de euros. Destacan entre sus objetivos: preservar y valorar la diversidad cultural y lingüística y el patrimonio cinematográfico y audiovisual europeo; potenciar el diálogo intercultural; incrementar la circulación de obras audiovisuales dentro y fuera de Europa y mejorar la competitividad del sector audiovisual europeo en el marco de un mercado abierto que favorezca el empleo. Su actuación se concentra así en la fase de preproducción, por medio del desarrollo de iniciativas destinadas a mejorar la formación y la capacidad de gestión de profesionales del cine, y en la de postproducción-distribución, difusión y promoción del cine europeo. ${ }^{6}$

En la misma línea Eurimages, fondo de ayuda a la coproducción, distribución y exhibición, creado bajo los auspicios del Consejo de Europa en 1989 y del que España es cofundador, cuenta con la participación de 36 países europeos (los de la Unión Europea con la excepción de Malta, Reino Unido, además de Noruega, Islandia, Suiza, Croacia, Serbia, Bosnia-Herzegovina, Macedonia, 
Turquía, Albania, Rusia, Georgia). Más del $50 \%$ de las película europeas son coproducciones, la mayoría con Eurimages, y buena parte de ellas llegan a los festivales de San Sebastián, Venecia, Berlín y Cannes, foros clave para afianzar su prestigio.

Además de abrir mercados y dinamizar la industria, las coproducciones facilitan el intercambio de profesionales y artistas y permiten el acceso a los beneficios económicos y fiscales disponibles en los países colaboradores. No olvidemos que en los últimos cuatro años el porcentaje de coproducciones respecto al total es muy estable, oscilando entre el 24 y el $27,5 \%$ ?

Otro factor clave para explorar la transnacionalidad es la distribución. La correlación entre el éxito del cine hollywoodiense y el control de la distribución por parte de compañías estadounidenses se hace patente en España. De las diez primeras distribuidoras españolas seis corresponden a filiales de Hollywood (Hispano Fox Films, The Walt Disney Company Iberia, Sony Pictures Releasing de España, United International Pictures and Cia, Universal Pictures International Spain, y Warner Bros Entertainment España), tres son empresas españolas (Aurum Producciones, Tripictures, Lauren Films) y una es una fusión entre una distribuidora española y otra americana (Warner-Sogefilms). Vemos así cómo no solo las distribuidoras hollywoodienses acaparan la mayor parte del mercado español, sino que además se asocian con distribuidoras locales para distribuir también películas españolas y atenuar su imagen colonizadora, minimizando a la vez el impacto de las medidas proteccionistas en España. Consecuencia de este modelo es el desequilibrio entre las películas españolas exhibidas y las hollywoodienses (entre año 2000 y 2010 llegaron a las pantallas entre 288 y 411 españolas y 1378 y 1555 norteamericanas). ${ }^{8}$ Junto a esto según los datos de la memoria de la FAPAE del 2013 la cuota de mercado por recaudación del cine español en el 2013 fue del 14\% y la del cine de Hollywood del 69,28\%.

Igualmente significativa es la presencia del cine español fuera del territorio nacional. Durante 2012 las producciones cinematográficas españolas 
recaudaron un $36 \%$ más en los mercados internacionales que en las salas españolas, 150 millones de euros frente a 110 millones de euros. México fue el país en el que el cine español obtuvo una mayor recaudación (17,7 millones de euros) seguido de Italia con 17,1 millones, Estados Unidos (16,4 millones), Francia (13,2) y Argentina (11,4). En el 2012 se exhibieron 141 películas españolas en el extranjero, lo cual supone un aumento de casi el doble que el año anterior. ${ }^{9} \mathrm{Si}$ bien como se ha mostrado la industria cinematográfica española se ve obligada a reconciliar las ventajas e inconvenientes de esta dinámica transnacional de los mercados, lo cierto es que genera una sinergia que permite ampliar los horizontes de nuestro cine.

\section{Sujetos transnacionales}

Los constantes desplazamientos de directores, actores y técnicos dentro de la industria cinematográfica actual corroboran el acercamiento de Akbar Abbas al cine, arte de la imagen en movimiento, como metáfora del dinamismo de la ciudad contemporánea. Al margen del paradigmático caso de Buñuel como pionero y como modelo de lo que Hamid Naficy denomina "accented cinema", la transnacionalidad de los cineastas actuales responde más a una elección personal basada en preferencias profesionales que a coyunturas políticas. Aunque estos movimientos multidireccionales han sido una constante desde los comienzos de la historia del cine lo que ha cambiado es su modo de interactuar con el concepto de cine nacional. Por un lado cineastas como Pedro Almodóvar anclan geográfica y culturalmente su obra en territorio nacional pero juegan con una temática, una estética, un repertorio genérico y un elenco de actores en continuo diálogo con nuestro presente global, y con Hollywood en particular. Por otro, directores como Isabel Coixet, además de filmar fuera del territorio nacional, desvinculan su obra de los marcadores de “españolidad”. Entre ambos polos, obras como las de Alejandro Amenábar, con un variado repertorio estético, temático e idiomático, suscitan una relación 
más compleja con lo español. Baste pensar en textos como The Others, The Secret Life of Words, My Live Whithout Me que, además de estar filmados en inglés, se instalan en espacios físicos ajenos España y abordan cuestiones políticas supranacionales -violencia, tortura, derechos humanos-o problemas universales-muerte, enfermedad. ${ }^{11}$ Con ellos conviven dentro de la filmografía de este director películas enraizadas en la realidad española como Mar adentro y Tesis. Otros cineastas como Julio Medem, además de oscilar entre polos opuestos en lo que atañe a la temática y a las localizaciones, abarcando tanto cuestiones vinculadas a la identidad nacional como ajenas a ella (La pelota vasca, Vacas, Lucía y el sexo, Los amantes del círculo polar) han optado por acercarse a Estados Unidos.

Un paso más en esta trayectoria lo marcan directores cuya carrera ha empezado en España y se ha consolidado en Hollywood como Juan Antonio Bayona, Juan Carlos Fresnadillo, Nacho Vigalondo y los hermanos Alex y David Pastor. ${ }^{12}$ El tipo de proyectos en los que se involucra esta nueva generación de directores responde a su cercanía a la estética de Hollywood, a la debilidad de la industria cinematográfica española y al privilegio de trabajar con presupuestos altos.

En el caso de los actores, su movilidad y en especial su presencia en Hollywood con la atención mediática que les granjea, continúan una trayectoria abierta ya en los años treinta y reconfirman el peso de Estados Unidos como catalizador a la hora de proyectar su carrera a nivel nacional y global. El éxito de figuras como Penélope Cruz, Javier Bardem y Antonio Banderas en Hollywood, la relativa popularidad de Paz Vega, Elsa Pataky, Elena Anaya, Jordi Mollá, Santiago Segura, Eduardo Noriega se traduce en un reconocimiento dentro y fuera de su país que raramente hubieran alcanzado sin el respaldo de Hollywood. 


\section{Registros estéticos}

En un momento en el que los modos de filmar al igual que el resto de las corrientes estéticas circulan con gran agilidad a nivel global, resulta difícil delimitar las fronteras del lenguaje cinematográfico y más aún adscribirlo a un país concreto. Los marcadores estilísticos de los directores españoles dialogan con la estética del cine europeo y hollywoodiense hasta llegar a crear un producto visualmente atractivo en varios contextos. Así, innovaciones formales como la fragmentación, la reflexividad, la ruptura de la linealidad temporal etc., que hasta época reciente tenían una limitada cabida en el cine español, forman ahora parte de su entramado. Además, el éxito y la difusión del cine americano independiente, paradójicamente vinculado en gran medida a las grandes productoras de Hollywood, impulsa esta ágil circulación de tendencias estéticas. Con ello las fronteras entre el cine de Hollywood, el cine independiente americano, los cines nacionales y el cine español en concreto se perciben cada día más borrosas. La resistencia al cine de Hollywood a la que en principio aspira el cine transnacional se atenúa a nivel estético en la medida en que la tradicional dicotomía entre sus marcadores-transparencia, linealidad, invisibilidad en el montaje-y los de los cines nacionales-ambigüedad, discontinuidad, autoconsciencia_resulta cada vez más tenue.

Una figura clave en este proceso de expansión es la del "productor-autor" como lo denomina Marvin D'Lugo (30) invirtiendo el aforismo de Walter Benjamin- "author as producer". En esta categoría enmarca a una serie de productores-autores españoles a partir del tardofranquismo-Elías Querejeta, Luis Borau, Andrés Vicente Gómez, Gerardo Herrero y Agustín Almodóvarembarcados en mayor o menor grado en la empresa de hacer llegar el cine español a las pantallas de otros países. Como bien muestra el estudio de D'Lugo cada uno de ellos activa unas estrategias determinadas, bien sea la adopción de la estética de Hollywood, la promoción de "autores" prestigiosos, la contratación de actores internacionalmente reconocidos, la borradura de la 
españolidad o su tratamiento de un modo legible para un público no español, siempre con el fin de cerrar la brecha entre los gustos del espectador español y los del global.

Vemos con ello cómo el repertorio de recursos textuales y discursivos que activa el cine español y la absorción de estilos codificados facilitan su inserción en esta estética transnacional que se debate entre subrayar y difuminar los trazos identitarios nacionales.

\section{Repertorio temático y tratamiento espacial}

La temática que recorre tanto la producción cinematográfica hollywoodiense como la perteneciente a las cinematografías nacionales refleja una serie de intereses e inquietudes que trascienden el espacio geográfico en el que se gestan para instalarse en un nivel supranacional. A la zaga de la globalización económica emerge una serie de temas que directa o metafóricamente reflejan y construyen la compleja realidad del tercer milenio.

El localismo temático al que nos tenía acostumbrados el cine español se diluye en beneficio de una universalidad que reproduce y estimula este constante intercambio de sujetos y de bienes propio de nuestra época. Lejos de anquilosarse en la reproducción de un legado cultural reconocible, el cine español actual aspira a elaborar un discurso que transcienda este marco. Ello no implica renunciar a la representación de temas netamente españoles sino dotarlos de nuevos significados, a la vez reconocibles y exportables. ${ }^{13}$

A su vez el ciudadano global, capaz de deslizarse sin apenas fricción de su registro nacional al supranacional, decodifica sin esfuerzo esta pluralidad de historias que intencionalmente renuncian a lo local en beneficio de una difusión fluida.

Junto con una temática esencialmente nacional, el repertorio temático español incorpora y refleja las inquietudes universales que atraviesan nuestro presente: desiguales relaciones de poder entre sujetos y naciones, memoria 
histórica, inmigración, violencia, marginalidades, problemas postcoloniales, dilemas éticos con resonancia universal. La obra de Icíar Bollaín, Fernando León, Isabel Coixet, Pedro Almodóvar, Julio Medem entre otros da buena muestra de este repertorio temático.

Dicha accesibilidad estimulada por una temática universal no impide la proliferación de lecturas diferentes en función del contexto en el que se visualiza un texto fílmico ni la potenciación de una identificación más profunda entre dicho texto y el contexto cultural en el que se gesta.

Como telón de fondo de esta temática, la elección de las localizaciones en las que se insertan estas historias revela la necesidad de crear un marco espacial amplio que de forma metafórica duplique la dislocación geográfica inherente al cine transnacional. Conviven así espacios reconocibles como iconos de España o de una ciudad determinada con lugares intencionalmente inidentificables, soporte de unos sujetos móviles propulsados por la globalización. Ello explica que motivos con la inmigración, el viaje con su consiguiente pertenencia o no pertenencia, ocupen una posición central en el cine actual. Flores de otro mundo, Poniente, 14 kilómetros, Salvajes, Cosas que dejé en la Habana, Cartas de Alou entre otras muchas reflejan bien la dinámica entre el tema y la localización. Los sujetos que dan vida a estos textos se desplazan constantemente insertando su existencia en un ámbito supranacional e incorporando la inestabilidad y el movimiento a la coyuntura histórica del siglo XXI.

\section{Componente ético e ideológico}

A nivel ético e ideológico el cine español actual, al igual que el resto de las cinematografías nacionales, aspira a contrarrestar el carácter pretendidamente inocuo de Hollywood y a insertar el compromiso en su modo de crear. Así el contenido y la forma responden ahora a los intereses de un público dispuesto a superar la barrera del mero entretenimiento y a incorporar la reflexión y el compromiso a su experiencia espectatorial. Con ello la plasmación de 
unos valores éticos determinados vinculados a la problemática social de momento se erige como componente clave en la construcción del texto. Las inquietudes sociales que atraviesan el cine español y su voluntad de mantener una integridad ética no implican rechazar de forma categórica las premisas del cine hollywoodiense sino supeditarlas a los parámetros del cine español y adaptarlas a su proyecto ideológico.

Los debates político-sociales de la España actual-inmigración, desempleo, desequilibrios económicos, memoria histórica, violencia de género, corrupción,- -entran en el campo de la ficción y desde ella vuelven a la realidad para intervenir en su construcción. En este contexto las iniciativas del gobierno y de organizaciones privadas para diseminar el cine español -por ejemplo Madrid de $\mathrm{Cine}^{14}$ — se rigen por una lógica que aspira a reconciliar unos valores propios con las exigencias de la industria. De este modo contribuyen a fomentan un tipo de cine pensado para llegar a un espectador por un lado sensible a cuestiones éticas y por otro capaz de entender esta simbiosis entre las inquietudes que afectan a España y al resto del mundo.

\section{Recepción crítica y espectatorial.}

Inseparable del componente ideológico, la recepción crítica y espectatorial refleja la adecuación o inadecuación entre el contenido de los textos y los intereses y valores de sus destinatarios. En un país como España, con una industria cinematográfica subvencionada durante casi cuarenta años por un gobierno autoritario, resulta difícil para el espectador desvincular el cine de la ideología. De este legado y de la veta realista que atraviesa el arte español deriva en parte la conexión del cine con el compromiso, no como imposición ahora, sino como réplica de las inquietudes de un presente que aspira a conectar con un espectador transnacional.

Si bien compartir una cultura, una lengua y unos valores garantiza la conexión con el espectador nacional, llegar a un espectador transnacional exige 
activar una serie de recursos, entre ellos la publicidad y la crítica, destinados a impulsar la difusión del cine fuera de su ámbito inmediato.

La crítica actual, propulsada por la velocidad y omnipresencia que ofrecen los medios de comunicación (prensa, televisión, blogs, revistas especializadas, académicas y de difusión) tanto en soporte material como virtual, opera como instrumento susceptible de configurar dicho espectador universal, educado para dirigir su mirada hacia unos intereses supranacionales. Gestado en este espacio virtual emerge un receptor/crítico ubicuo, no profesional, que si bien no tiene gran poder para influir en la recaudación de taquilla, si lo tiene para crear una comunidad de espectadores abierta a textos fílmicos que quedan fuera del circuito publicitario de Hollywood. Se trata así de reconciliar la lógica dual que afecta la recepción del cine transnacional: por un lado la dificultad de llegar a un espectador multicultural, cambiante y por otro la ventaja de acceder de forma inmediata y sin condicionamientos espacio-temporales a dicho espectador plural.

Dentro de este mapa sin fronteras dibujado por los procesos de globalización emergen una serie de espacios de difusión natural para el cine español que abarcan comunidades y países con lazos culturales con España. Latino America y Europa operarían así como ámbitos propicios para una recepción abierta debido a la existencia de un legado histórico común y de un presente plagado vínculos humanos y económicos.

Junto a esto la liminalidad que enmarca la recepción de cine español fuera de su contexto, propicia acercamientos abiertos, diversos e inevitablemente distintos de los gestados en el marco nacional. Como bien apunta Gledhill "Meaning is neither imposed, nor passively imbibed, but arises out of a struggle or negotiation between competing frames of reference, motivation and experience" (101). De ahí la necesidad de negociar las inquietudes éticas y estéticas del espectador global con los registros del cine español, de llegar a una audiencia heterogénea y de crear un marco crítico operativo dentro de la 
realidad del tercer milenio.

A modo de conclusión y a partir del acercamiento propuesto en este estudio, resulta imprescindible tener en cuenta la interconexión de las categorías aquí propuestas para explorar la transnacionalidad de nuestro cine, la imposibilidad de entenderlas como compartimentos estanco ya que todas ellas se superponen y dialogan dentro de un mismo texto fílmico, complicando su delimitación. Si bien es cierto, como se ha apuntado antes, que la transnacionalidad del cine en general y del español en particular se remonta prácticamente a los orígenes del séptimo arte, el modo de entender este fenómeno ha cambiado radicalmente. En nuestro presente, marcado por el signo de la globalización, el marco estético y geo-político de interacción se ha dilatado considerablemente con el fin de apelar a la sensibilidad de un espectador supranacional. La transnacionalidad del cine español tal y como la entendemos ahora impone un modo de crear capaz de activar un abanico de imágenes gestadas dentro y fuera del territorio nacional, reconocibles a nivel global y susceptibles de agilizar la circulación de nuestra producción cinematográfica. Ello no implica anular los vestigios de un cine nacional que se debate entre su disolución y permanencia, dispuesto a atenuar, reciclar o incluso borrar su españolidad en beneficio de una recepción más amplia, sino incorporar nuevas formas de crear imágenes. Se trata así, como bien explica Vicente Rodríguez Ortega, de explorar las “zonas de contacto", de calibrar las interconexiones entre lo local, lo nacional y lo global en unos contextos de producción, distribución y recepción que ignoran las fronteras, de superar la eterna dicotomía entre el cine de Hollywood y el cine del resto del mundo. Solo a partir de un acercamiento abierto a la simbiosis entre lo propio y lo ajeno podremos calibrar la gestación de nuestro cine, su difusión y su recepción en un espacio geopolítico amplio, difícil de dibujar. 


\section{Notas}

1 Además de los citados en este trabajo destacan los siguientes estudios: Katherine Newman. "Notes on Transnational Film Theory". World Cinema, Transnational Perspectives. Eds. Natasa Durovicova and Kathleen Newman. Routledge, 2010 (3-11); Juan Poblete, "New National Cinemas in a Transnational Age", Discourse 26.1 \& 26.2 (2004): 214-234; Elizabeth Ezra and Terry Rowden. Eds. Transnational Cinema: A Film Reader. Routledge, 2006; Nayibe Bermúdez Barrios. Ed. Latin American Cinemas. Local Views and Transnational Connections. Calgary: University of Calgary Press, 2011; Andrew Nestingen and Trevor Elkington. Eds. Transnational Cinema in a Global North. Wayne University Press, 2005; José Colmeiro. "El discreto encanto del sueño americano: Hollywood y el nuevo cine español". Ventanas sobre el Atlántico: Estados Unidos y España durante el postfranquismo (1975-2008). Eds. Carlos X. Ardavín y Jorge Marí. Publicaciones de la Universidad de Valencia, 2011 (99-115); Alejandro Pardo y Alfonso Sánchez-Tabernero. "Concentración de la distribución cinematográfica en España”. Analisi 47 (2012 37-56. Igualmente destacan un número especial de la revista Hispanic Research Journal. The Transnational in Iberian and Latin American Cinemas editado por Chris Perrian, Isabel Santaolalla, Peter Evans y la revista Transnational Cinemas dedicada a este tema.

2 Se han activado también modelos más precarios de financiación como el 'crowdfunding', 'brandfunding' o incluso cooperativas artísticas con limitados recursos que ayudan a producir películas de bajo coste que probablemente no llegarán a salas comerciales y solo se verán por otros canales como Internet, festivales, cineclubs.

3 Para un estudio detallado de Ibermedia consultar el trabajo de Tamara Falicov. “Ibero-Latinamerican Co-productions: Transnational Cinema, Spain's Public Relations Venture or Both". Contemporary Spanish Cinema. Interrogating the Transnational in Spanish and Latin American Film. Ed. Stephanie Dennison. Tamesis, 2013 (67-88).

4 Tomo el dato de la página de Ibermedia http://www.programaibermedia.com/ nuestras-noticias/convocatoria-2014-274-proyectos-presentadosconvocatoria2014-274-proyectos-presentados/ 
5 Chris Perriam, Isabel Santaolalla y Peter Evans en la introducción al número de Hispanic Research Journal editado por ellos, The Transnational in Iberian and Latinamerican Cinemas, refiriéndose a Ibermedia apuntan: "On the one hand Spain on film is both inward-looking and, in its international self- projections, apparently caught up in the Northern Trans-Atlantic binary" (5).

6 Para una vision sobre el modelo de financiación europeo consultar: http://europa. eu/legislation summaries/audiovisual and media/l24224a es.htm

7 Tomo el dato de Academia. Revista de Cine Español, número 200, mayo 2013.

8 La información procede del artículo publicado por Alejandro Pardo y Alfonso Sánchez-Tabernero, "Concentración de la distribución cinematográfica en España". Analisi vol. 47, 2012, pp. 37-56.

9 Es importante tener en cuenta el factor coyuntural ya que películas tan exitosas como Lo imposible (2012) de Juan Antonio Bayona, -la película más taquillera de España con una recaudación de 41 millones y casi 6 millones de espectadoresdistorsionan las estadísticas.

10 Hamid Naficy identifica a los directores de lo que él llama "accented cinema" como "situated but universal figures who work in the interstices of social formations and cinematic practices" (10).

11 Si bien The Others se filmó en la provincia de Santander, su localización ficticia nos lleva a la isla de Jersey.

12 Un artículo aparecido en Fotogramas 20 enero 2013 resume la trayectoria de estos directores cuya carrera despega en Estados Unidos. http://www.fotogramas.es/ Noticias-cine/Bayona-y-otros-directores-espanoles-en-Hollywood

13 Alejandro Yarza en Un caníbal en Madrid ha analizado este reciclaje de estereotipos nacionales en el cine de Almodóvar y su habilidad para abrirlos a nuevas lecturas.

14 Entre los organizadores de la última edición de Madrid de Cine figuran la FAPAE (Confederación de productores audiovisuales españoles), ICSS (Instituto de la Cinematografía y de las Artes Audiovisuales), ICEX (España Exportación e Inversiones), la Consejería de Empleo, Turismo y Cultura de la Comunidad de Madrid, EGEDA (Entidad de Gestión de Derechos de los Productores Audiovisuales, Acción Cultural Española y el Ayuntamiento de Madrid. (http://www. madriddecine.es) 


\section{Obras Citadas}

Bermúdez Barrios, Nayibe. Ed. Latin American Cinemas. Local Views and Transnational Connections. University of Calgary Press, 2011.

Christie, Ian. "Where is National Cinema Today (and do we still need it?)". Film History vol. 25, 2012, pp. 19-30.

Colmeiro, José. "El discreto encanto del sueño americano: Hollywood y el nuevo cine español”. Ventanas sobre el Atlántico: Estados Unidos y España durante el postfranquismo (1975-2008). Eds. Carlos X. Ardavín y Jorge Marí. Publicaciones de la Universidad de Valencia, 2011 pp. 99-115.

D’Lugo, Marvin. “Transnational Frameworks”. A Companion to Spanish Cinema. Ed. Jo Labanyi and Tatjana Pavlovic. Willey-Blackwell 2013, pp. 15-49.

Ezra, Elizabeth and Terry Rowden. Eds. Transnational Cinema: A Film Reader. Routledge, 2006.

Gledhill, C. "Pleasurable Negotiations". Cultural Theory and Popular Culture: A Reader. Ed. J. Storey. Pearson, 2009, pp. 98-110.

Higbee, Will and Song Hwee Lim. "Concepts of transnational cinema: towards a critical transnationalism in film studies”. Transnational Cinemas vol. 1, no. 1, 2010, pp. 7-21.

Hjort, Mette. "On the Plurality of Cinematic Transnationalism". World Cinemas, Transnational Perspectives. Eds. Natasa Durovicova and Kathleen Newman. Routledge, 2010, pp. 12-33.

Khorana, Sukhmani. Crossover Cinema: cross-cultural film from production to reception Ed. Sukhmani Khorana. Routledge, 2013.

Naficy, Hamid. An Accented Cinema. Princeton University Press, 2001.

Nestingen, Andrew and Trevor Elkington. Eds. Transnational Cinema in a Global North. Wayne University Press, 2005.

Newman, Katherine. "Notes on Transnational Film Theory". World Cinema,

Transnational Perspectives. Eds. Natasa Durovicova and Kathleen Newman. Routledge, 2010 pp. 3-11.

Pardo, Alejandro y Alfonso Sánchez-Tabernero, "Concentración de la distribución cinematográfica en España”. Analisi vol. 47, 2012, pp. 37-56.

Perriam, Chris, Isabel Santaolalla and Peter Evans. "The Transnational in Iberian and Latinamerican Cinemas”. Hispanic Research Journal vol. 8, no. 1, 2007, pp. 3-9. 
Poblete, Juan. “New National Cinemas in a Transnational Age”. Discourse vol. 26, no. 1-2, 2004, pp. 214-234.

Rodríguez Ortega, Vicente. Transnational Media Imaginaries: Cinema, Digital Technology and Uneven Globalization. Dissertation. Ann Arbor. 2007. http://search.proquest. com/docview/304840123/abstract.

Shaw, Deborah. "Deconstructing and Reconstructing 'Transnational Cinema'”. Contemporary Hispanic Cinema. Interrogating the Transnational in Spanish and Latin American Film. Ed. Stephanie Dennison. Tamesis, 2013, pp. 47-65.

Triana Toribio, Nuria. "Building Latin American Cinema in Europe: Cine en Construcción/Cinema en Construction. Contemporary Hispanic Cinema. Interrogating the Transnational in Spanish and Latin American Film. Ed. Stephanie Dennison. Tamesis, 2013, pp. 89-112.

Villazana, Libia. "Redefining Transnational Cinemas: A Transdisciplinary Perspective”. Contemporary Hispanic Cinema. Interrogating the Transnational in Spanish and Latinamerican Films. Ed. Stephanie Dennison. Tamesis, 2013, pp. 25-46. 